\title{
Penerimaan Diri sebagai Mediator Hubungan antara Religiusitas dengan Kecemasan pada Penyandang Diabetes Mellitus Tipe 2
}

\author{
Mariyana Widiastuti1), Kwartarini Wahyu Yuniarti²) \\ 1) Fakultas Psikologi Universitas Gadjah Mada, Yogyakarta \\ Email : mariyana.widiastuti@gmail.com \\ 2) Fakultas Psikologi Universitas Gadjah Mada, Yogyakarta \\ Email : kwartarini.yuniarti@gmail.com
}

\begin{abstract}
Diabetes mellitus merupakan salah satu penyakit yang bersifat kronis dan penyandangnya tidak dapat sembuh secara sempurna. Berdasarkan hasil penelitian yang telah dilakukan, pasien diabetes rentan mengalami kecemasan. Penelitian ini bertujuan untuk menguji secara empirik hubungan antara religiusitas dengan kecemasan melalui penerimaan diri sebagai mediator pada pasien diabetes mellitus tipe 2 . Penelitian ini melibatkan 78 orang penyandang diabetes mellitus tipe 2 yang berusia 40-70 tahun. Pengumpulan data menggunakan 3 alat ukur yaitu Skala Religiusitas, Skala Penerimaan Diri dan Skala Kecemasan. Data dianalisis menggunakan analisis mediasi Sobel test. Hipotesis yang diajukan dalam penelitian ini ada 3, yaitu: (1) ada hubungan negatif antara tingkat religiusitas dengan kecemasan pada penyandang diabetes mellitus tipe 2 , (2) ada hubungan positif antara tingkat religiusitas dengan penerimaan diri pada penyandang diabetes mellitus tipe 2, (3) ada hubungan negatif antara tingkat religiusitas melalui penerimaan diri dengan kecemasan pada penyandang diabetes mellitus tipe 2 . Hasil penelitian menunjukkan bahwa terdapat hubungan negatif yang signifikan antara religiusitas dengan kecemasan pada penyandang diabetes tipe 2 , dengan $(\beta)$ sebesar $-0,5912 ; p=0,0263(p<0,05)$. Ada hubungan positif yang signifikan antara religiusitas dengan penerimaan diri pada penyandang diabetes tipe 2 , dengan $(\beta)$ sebesar 0,5134; $p=0,0006(p<0,01)$. Analisis mediasi Sobel Test menunjukkan ada hubungan negatif antara religiusitas melalui penerimaan diri dengan kecemasan pada penyandang diabetes tipe 2 sebesar $-0,6961 ; p=0,0019(p<0,01)$. Hasil tersebut menunjukkan bahwa penerimaan diri menjadi mediator hubungan antara religiusitas dengan kecemasan pada penyandang diabetes tipe 2 .
\end{abstract}

Kata kunci: religiusitas, penerimaan diri, kecemasan, diabetes mellitus tipe 2

\section{PENDAHULUAN}

$\mathrm{M}$ enuju Indonesia sehat pada tahun 2010 adalah gambaran masyarakat Indonesia di masa depan yang ingin dicapai melalui pembangunan kesehatan yang ditandai oleh kehidupan dalam lingkungan dan perilaku yang sehat, baik sehat jasmani, rohani, serta sosial dan bukan hanya keadaan bebas dari penyakit, cacat dan kelemahan (Winasis, 2009). Visi Indonesia sehat yang diharapkan itu nampaknya belum mampu diterapkan di Indonesia saat ini. Hal ini ditunjukkan dengan angka prevalensi penyakit diabetes mellitus yang terus meningkat (Yudo,
2009). Jumlah penderita diabetes yang terus meningkat di Indonesia perlu diwaspadai karena kini Indonesia menempati urutan keempat terbesar dunia yaitu 8,4 juta orang setelah India, China, dan Amerita Serikat (Asmadi, 2008). Secara epidemiologi, diperkirakan bahwa pada tahun 2030 penyandang diabetes di Indonesia mencapai 21,3 juta orang (Yudo, 2009). Data dari Departemen Kesehatan menunjukkan jumlah pasien diabetes rawat inap maupun rawat jalan di rumah sakit menempati urutan pertama dari seluruh penyakit endokrin (Asmadi, 2008). Hasil Riset kesehatan Dasar (Riskesdas) tahun 2007, diperoleh bahwa proporsi penyebab 
kematian akibat diabetes pada kelompok usia 45-54 tahun di daerah perkotaan menduduki ranking ke- 2 yaitu $14,7 \%$, dan di daerah pedesaan diabetes menduduki ranking ke-6 yaitu 5,8\% (Yudo, 2009).

Diabetes mellitus, yang selanjutnya disebut dengan diabetes juga dikenal di Indonesia dengan istilah penyakit kencing manis atau penyakit gula. Diabetes adalah gangguan metabolisme yang disebabkan oleh banyak faktor dengan simtom berupa hiperglisemia kronis dan gangguan metabolisme karbohidrat, lemak dan protein, sebagai akibat dari defisiensi sekresi atau resistensi hormon insulin (Taylor, 2006). Hiperglisemia sendiri merupakan kelebihan gula dalam darah dalam jangka waktu yang lama, dan digunakan sebagai tanda seseorang menderita diabetes (Sarafino, 1998). Khususnya pada diabetes mellitus tipe 2, diabetes jenis ini dikenal sebagai diabetes tidak tergantung insulin. Diabetes mellitus tipe 2 berkembang ketika tubuh masih mampu menghasilkan insulin tetapi tidak cukup atau insulin yang dihasilkan tidak bekerja secara sempurna (Asmadi, 2008; Sarafino, 1990; Taylor, 2006). Sekitar 9095\% penderita diabetes memiliki tipe ini (Asmadi, 2008; Sousa, Hartman, Miller, \& Carroll, 2009) dan biasanya muncul pada usia 40 tahun ke atas (Taylor, 2006).

Diabetes merupakan kumpulan gejala yang timbul pada seseorang yang disebabkan karena adanya peningkatan kadar gula darah (glukosa) akibat kekurangan insulin baik absolut maupun relatif (Sarafino, 1998). Diabetes mulai menonjol sebagai penyebab mortalitas di negara-negara sedang berkembang termasuk di negara Indonesia (Winasis, 2009), sehingga penyandangnya perlu mengambil tanggung jawab atas perawatan dirinya dengan tujuan untuk mempertahankan kadar gula dan tekanan darah agar dapat mendekati normal (Paul, Smith, Whitford, O'Shea, O'Kelly, \& O'Dowd, 2007). Suyono mengemukakan bahwa selama bertahun-tahun penderita hidup dengan diabetes akan memungkinkan munculnya berbagai kerusakan atau komplikasi pada penderitanya. Lebih rumit lagi diabetes tidak menyerang satu alat tubuh saja, tetapi dapat menyerang beberapa alat tubuh sekaligus dan dapat menyebabkan terjadinya komplikasi yang dapat diidap bersamaan dalam satu tubuh (Suyono, 2009). Tingginya angka prevalensi penderita diabetes tentu saja membutuhkan perhatian, terlebih lagi karena diabetes juga dapat menyerang di semua bagian tubuh dan dapat menyebabkan kematian.

Diabetes merupakan penyakit kronis sehingga penyandangnya tidak dapat sembuh secara sempurna dan perlu perawatan seumur hidup, dapat menimbulkan perubahan psikologis yang mendalam pada pasien, juga pada keluarga dan kelompok sosialnya (Winasis, 2009). Pada seseorang yang telah didiagnosis menderita diabetes biasanya timbul ketakutan (Winasis, 2009).

Kecemasan, depresi dan diabetes distres adalah kondisi umum yang dialami oleh penyandang diabetes (Collins, Corcoran, \& Perry, 2008; Fisher, Skaff, Mullan, Areant, Glasgow, \& Masharani, 2008; Khuwaja, et al., 2010; Li, Barker, Ford, Zhang, Strine, \& Mokdad, 2008; Roupa, Koulouri, Sotiropoulou, Makrinika, Marneras, Lahana, \& Gourni, 2009) dan kesemuanya berhubungan dengan berbagai variabel biobehavioral seperti: manajemen sakit yang buruk, tingginya biaya perawatan kesehatan, buruknya kinerja, dan juga kematian (Fisher et al., 2008). Hal serupa juga diungkapkan oleh Roupa dan kawankawan bahwa seseorang yang menyandang diabetes akan terbebani oleh faktor sosiodemografi serta faktor-faktor perilaku lainnya yang berkontribusi pada manifestasi simtom-simtom kecemasan (Roupa et al., 2009). Adanya gangguan kecemasan ini disebabkan ketidakmampuan penyandang diabetes dalam keberfungsiannya maupun dalam mengatur tingkat gula darah yang ada dalam dirinya (Paddison, Eborall, French, Kinmonth, Prevost, Griffin, \& Sutton, 2011; Winasis, 2009). Menurut Taylor (2006), kecemasan tidak hanya merupakan distres secara intrinsik tetapi juga dapat mengganggu keberfungsian yang baik. Kecemasan yang dialami seseorang dapat dikategorikan menjadi dua jenis yaitu, trait anxiety dan state anxiety. Trait anxiety dapat juga disebut sebagai kecemasan sifat, artinya cemas yang dialami oleh seseorang sudah melekat pada dirinya dan menjadi salah satu 
ciri kepribadiannya. State anxiety merupakan kecemasan yang terjadi secara temporer, yang tercermin pada respon seseorang terhadap situasi tertentu (Alloy, Riskind, \& Manos, 2005).

Pada penyandang diabetes kecemasan yang dialami termasuk dalam state anxiety, yang berarti bahwa kecemasan tersebut muncul karena diabetes yang sedang dialaminya. Kecemasan yang muncul pada penyandang diabetes dapat menyebabkan buruknya kontrol gula darah sehingga dapat meningkatkan simtomsimtom kecemasan itu sendiri (Taylor, 2006), social impairment, occupational impairment, dan fungsi area penting lainnya (Hall \& Hall, 2010). Taylor (2006) selanjutnya menambahkan bahwa kecemasan ialah suatu pengalaman subjektif mengenai ketegangan mental yang menggelisahkan sebagai reaksi umum dari ketidakmampuan menghadapi masalah atau tidak adanya rasa aman. Perasaan yang tidak menyenangkan ini umumnya menimbulkan gejala-gejala fisiologis seperti: gemetar, berkeringat, detak jantung meningkat, dan lain-lain; dan gejala-gejala psikologis seperti: panik, tegang, bingung, tak dapat berkonsentrasi, dan sebagainya (Maramis, 1998; Pinel, 1997; Taylor, 2006). Sejalan dengan Taylor, kecemasan menurut Durand dan Barlow (2006) adalah keadaan suasana hati yang ditandai oleh afek negatif dan gejala-gejala ketegangan jasmaniah di mana seseorang mengantisipasi kemungkinan datangnya bahaya atau kemalangan di masa yang akan datang dengan perasaan khawatir, dan kecemasan sendiri melibatkan perasaan, perilaku, dan respon-respon fisiologis. Berdasarkan beberapa pendapat di atas, maka dapat disimpulkan bahwa gejala-gejala kecemasan pada penyandang diabetes dapat berupa gejala fisiologis dan atau gejala psikologis.

Berdasarkan hasil penelitian yang telah dipaparkan di atas tampak bahwa penyandang diabetes berpotensi mengalami kecemasan sebagai akibat dari sakit yang disandangnya. Kecemasan tersebut muncul karena mereka harus melakukan banyak sekali penyesuaian diri baik yang terkait dengan pengobatan maupun pada perubahan pola makan dan aktivitas rutin
(Ambarwati, 2008; Soeharjono, Tjokroprawiro, \& Adi, 2002). Ada beberapa faktor yang dapat menyebabkan individu mengalami kecemasan. Faktor-faktor tersebut adalah faktor biologis, faktor sosial lingkungan, faktor behavioral, serta faktor kognitif dan emosional (Durand \& Barlow, 2006). Sebuah model biopsikososial yang komprehensif dapat menunjang penyandang diabetes untuk menerapkan hidup sehat dan harmonis (Sridhar \& Madhu, 2002). Konstruk biopsikososial tersebut menyatakan bahwa penyakit berasal dari interaksi dinamis antara faktor biologis, psikososial, perkembangan, sosialbudaya, dan faktor lingkungan. Tidak hanya individu yang berperan penting dalam manajemen diabetes, tetapi lingkungan juga mempengaruhi perilaku preventif dan kuratif. Dinamika antar reaksi terjadi dalam berbagai proporsi dan berlangsung sepanjang hidup (Sridhar \& Madhu, 2002).

Berdasarkan model biopsikososial yang telah dipaparkan di atas, aspek religiusitas dan penerimaan diri diduga memiliki hubungan dengan gangguan kecemasan yang dialami oleh pasien diabetes. Dari hasil penelitian yang telah dilakukan sebelumnya, religiusitas berhubungan dengan kecemasan yang dialami oleh pasien dengan penyakit kronis (Morse, Afifi, Morgan, Stephenson, Reichert, Harrison, \& Long, 2009), maupun pada orang-orang yang mengalami kecemasan menghadapi kematian (Dewi, 2008; Koenig, 2009) yaitu semakin tinggi tingkat religiusitas seseorang maka semakin rendah tingkat kecemasannya. Hal tersebut dijelaskan oleh Koenig bahwa religiusitas dapat merepresentasikan sumber kekuatan dari kenyamanan, harapan, dan kebermaknaan (Koenig, 2009). Religiusitas merupakan sebuah sistem yang terintegrasi dari kepercayaan, amalan, ritual, dan simbol-simbol yang dirancang untuk memfasilitasi kedekatan pada hal-hal yang dianggap suci atau sangat penting dalam hidup seseorang seperti Tuhan atau kepercayaan yang lainnya (Koenig, 2009).

Penelitian yang telah dilakukan sebelumnya menyebutkan bahwa religiusitas berhubungan positif dengan indikator-indikator kebermaknaan 
psikologis seperti kepuasan hidup, kebahagiaan, afek positif, derajat moral yang tinggi, serta mampu menurunkan tingkat depresi maupun kecemasan (Almeida, Neto, \& Koenig, 2006; Koenig, 2009; Lee \& Newberg, 2005; Seeman, Dubin, \& Seeman, 2003). Seybold dan Hill (2001) dalam penelitiannya menyimpulkan bahwa efek positif dari religiusitas dan spiritualitas adalah seseorang akan memiliki kesehatan fisik yang baik. Hasil penelitian mereka menunjukkan bahwa religiusitas dan spiritualitas berasosiasi dengan efek-efek fisiologis seperti: tekanan darah systole dan diastole yang relatif rendah, tingkat kolesterol, stres, penyakit hati, sirosis, kematian pada kanker, dan gagal ginjal yang relatif rendah pula, serta mampu meningkatkan perilaku hidup sehat dan menjadikan usia seseorang lebih panjang. Pargament dalam penelitiannya telah mengidentifikasi hubungan antara religiusitas dan kesehatan, dan menyimpulkan bahwa seseorang yang melibatkan Tuhan dalam kehidupannya sebagai koping ketika menghadapi stressor akan memiliki tingkat kecemasan yang rendah, fisik dan kesehatan mental yang baik, serta kompetensi psikososial yang baik pula (Hathaway \& Pargament, 1990; Pargament, 1997). Menurut Almeida (2006) terdapat beberapa mediator yang mampu menjelaskan mengapa religiusitas mampu mempengaruhi kesehatan mental seseorang. Mediator yang dijelaskan tersebut diantaranya adalah perilaku dan gaya hidup sehat, dukungan sosial, belief systems, dan sebagainya (Almeida et al., 2006).

Belief systems dan proses kognitif mampu mempengaruhi bagaimana seseorang menghadapi stres dan masalah dalam hidupnya sehingga menghasilkan kesehatan fisik dan mental yang baik (Almeida et al., 2006; Sloan, Padron, \& Platt, 2009). Religious belief dapat memberikan dukungan melalui penerimaan, kesabaran, ketabahan dan resiliensi (Pargament, Koenig, Tarakeshwar, \& Hahn, 2004). Berdasarkan teori belajar sosial, locus of control mencoba untuk menjelaskan mengapa orang memiliki cara yang berbedabeda ketika menghadapi masalah yang sama. Locus of control internal biasanya berhubungan dengan kebermaknaan hidup, sedangkan locus of control eksternal berhubungan dengan depresi dan kecemasan. Religious belief mampu menyokong internal locus of control sehingga mempengaruhi kesehatan mental seseorang (Almeida et al., 2006), mencegah seseorang melakukan tindakan yang membahayakan dirinya maupun orang lain, memotivasi perilaku prososial, meningkatkan rasa aman, dan mendorong rasa percaya diri seseorang (Koenig, 2009) yang kesemuanya merupakan hal-hal yang dapat menimbulkan kecemasan. Koping religius yang positif berasosiasi dengan kesehatan mental yang baik karena mampu mempengaruhi perilaku seseorang seperti: mencari dan menemukan Tuhan ketika menghadapi stressor, mencari dukungan dari orang lain yang beriman, dan berpikir bahwa kehidupan seseorang adalah bagian dari rencana Tuhan (Almeida et al., 2006; Koenig, 2009). Berdasarkan hasil-hasil penelitian yang sudah dilakukan dapat disimpulkan bahwa religiusitas berperan dalam menurunkan tingkat kecemasan seseorang.

Adanya perubahan-perubahan pengaturan pola makan, penyuntikan insulin dan pengontrolan gula darah mampu membuat penyandang diabetes mengalami kecemasan (Ambarwati, 2008; Soeharjono et al., 2002). Selain aspek religiusitas yang diduga mampu menurunkan tingkat kecemasan, peranan penerimaan diri juga dibutuhkan bagi penyandang diabetes untuk membantu menyesuaikan diri dengan perubahan-perubahan yang dialaminya (Novvida, 2007). Sejalan dengan beberapa penelitian yang telah dilakukan sebelumnya bahwa seseorang dengan tingkat penerimaan diri yang rendah memiliki tingkat kecemasan dan depresi lebih tinggi yang berkaitan dengan kesehatan fisiknya (Chamberlain \& Haaga, 2001; Flett, Besser, Davis, \& Hewitt, 2003; Macinnes, 2006). Badaria (2004) dalam penelitiannya mengenai diabetes menunjukkan bahwa terdapat hubungan yang signifikan antara religiusitas dan penerimaan diri. Dijelaskan bahwa penerimaan diri yang terjadi pada penyandang diabetes dipengaruhi dari tingkat religiusitas mereka (Badaria, 2004; Wardhani, 2007). Hasil penelitian tersebut menunjukkan bahwa penerimaan diri yang 
baik memberikan efek positif pada kesejahteraan psikologis seseorang.

Berdasarkan pemaparan di atas, dapat disimpulkan bahwa penyandang diabetes mellitus rentan mengalami kecemasan memerlukan aspek-aspek psikologis yang dapat membantu penyandang diabetes agar memiliki kesejahteraan psikologis yang lebih baik dan dapat mengurangi kecemasan (Collins et al., 2008, Fisher et al., 2008; Khuwaja et al., 2010; Roupa et al., 2009). Aspek religiusitas berperan sebagai dukungan spiritual dan mampu mengurangi beban psikologis (Pfeifer \& Waelty, 1999) sehingga dapat meningkatkan penerimaan diri (Badaria, 2004; Macinnes, 2006) serta menurunkan kecemasan bagi penyandangnya (Morse et al., 2009). Menurut Pargament (1997), keberhasilan mengintegrasikan pengalaman menghadapi penyakit dengan keyakinan spiritual akan mempengaruhi penerimaan penderita dan mampu mengurangi kecemasan yang dialaminya. Dengan demikian dapat dilihat bahwa variabel yang diperkirakan berhubungan dengan kecemasan adalah religiusitas dan penerimaan diri. Tujuan diadakannya penelitian ini adalah untuk mengetahui hubungan antara religiusitas dan penerimaan diri dengan kecemasan pada penyandang diabetes mellitus tipe 2 .

\section{TINJAUAN PUSTAKA}

Diabetes mellitus tipe 2 berkembang ketika tubuh masih mampu menghasilkan insulin tetapi tidak cukup atau insulin yang dihasilkan tidak bekerja secara sempurna (Asmadi, 2008; Sarafino, 1990; Taylor, 2006). Sekitar 90-95\% penderita diabetes memiliki tipe ini (Asmadi, 2008; Sousa, Hartman, Miller, \& Carroll, 2009) dan biasanya muncul pada usia 40 tahun ke atas (Taylor, 2006). Diabetes merupakan kumpulan gejala yang timbul pada seseorang yang disebabkan karena adanya peningkatan kadar gula darah (glukosa) akibat kekurangan insulin baik absolut maupun relatif (Sarafino, 1998).

Kecemasan, depresi dan diabetes distres adalah kondisi umum yang dialami oleh penyandang diabetes (Collins,
Corcoran, \& Perry, 2008) dan kesemuanya berhubungan dengan berbagai variabel biobehavioral seperti: manajemen sakit yang buruk, tingginya biaya perawatan kesehatan, buruknya kinerja, dan juga kematian (Fisher et al., 2008). Pada penyandang diabetes kecemasan yang dialami termasuk dalam state anxiety, yang berarti bahwa kecemasan tersebut muncul karena diabetes yang sedang dialaminya. Kecemasan yang muncul pada penyandang diabetes dapat menyebabkan buruknya kontrol gula darah sehingga dapat meningkatkan simtom-simtom kecemasan itu sendiri (Taylor, 2006), social impairment, occupational impairment, dan fungsi area penting lainnya (Hall \& Hall, 2010).

Taylor (2006) selanjutnya menambahkan bahwa kecemasan ialah suatu pengalaman subjektif mengenai ketegangan mental yang menggelisahkan sebagai reaksi umum dari ketidakmampuan menghadapi masalah atau tidak adanya rasa aman. Perasaan yang tidak menyenangkan ini umumnya menimbulkan gejala-gejala fisiologis seperti: gemetar, berkeringat, detak jantung meningkat, dan lain-lain; dan gejala-gejala psikologis seperti: panik, tegang, bingung, tak dapat berkonsentrasi, dan sebagainya (Maramis, 1998; Pinel, 1997; Taylor, 2006).

Religiusitas berhubungan dengan kecemasan yang dialami oleh pasien dengan penyakit kronis (Morse, Afifi, Morgan, Stephenson, Reichert, Harrison, \& Long, 2009). Hal tersebut dijelaskan oleh Koenig bahwa religiusitas dapat merepresentasikan sumber kekuatan dari kenyamanan, harapan, dan kebermaknaan (Koenig, 2009). Sedangkan Belief systems dan proses kognitif mampu mempengaruhi bagaimana seseorang menghadapi stres dan masalah dalam hidupnya sehingga menghasilkan kesehatan fisik dan mental yang baik. Religious belief dapat memberikan dukungan melalui penerimaan, kesabaran, ketabahan dan resiliensi (Pargament, Koenig, Tarakeshwar, \& Hahn, 2004).

\section{METODE}

Penelitian ini merupakan survei cross-sectional yang melibatkan 78 orang partisipan dengan kriteria sebagai berikut: 
1. Pasien diabetes tipe 2, baik laki-laki maupun perempuan.

2. Berusia antara 40-70 tahun.

3. Bersedia terlibat dalam penelitian dan telah menandatangani informed consent.

Beberapa alat ukur yang akan digunakan dalam penelitian ini antara lain: a) Skala Kecemasan dikembangkan oleh Ambarwati (2008) yang disusun berdasarkan manifestasi kecemasan yang terwujud dalam indikator-indikator fisiologis maupun psikologis (Maramis, 1998; Pinel, 1997; Taylor, 2006); b) Skala Religiusitas yang disusun oleh Dewi (2008) dengan korelasi aitem total 0,211 - 0,566 dan koefisien reliabilitas 0,781. Aspek-aspek dalam skala ini berdasarkan pendapat Glock dan Stark (Ancok, 1989) yang menyatakan bahwa ada lima dimensi religiusitas (keberagamaan), yang perlu diperhatikan untuk melihat tingkat religiusitas seseorang. Kelima dimensi tersebut adalah iman, ibadah, ihsan, amal dan ilmu; c) Skala Penerimaan Diri yang disusun oleh Novvida (2007) dengan korelasi aitem total 0,335 0,737 dan koefisien reliabilitas 0,923.

Teknik analisis yang digunakan untuk penelitian ini adalah dengan analisis mediator yaitu Sobel test. Sobel test digunakan untuk melihat pengaruh langsung variabel independen terhadap variabel dependen maupun pengaruh tidak langsung variabel independen terhadap variabel dependen melalui variabel mediator (Baron \& Kenny, 1986; Preacher \& Hayes, 2004).

\section{HASIL DAN PEMBAHASAN}

\section{a) Hasil}

Penelitian ini melibatkan 78 subjek yang berdomisili di Yogyakarta dan sekitarnya. Pengambilan data dilakukan dengan cara membagikan tiga skala penelitian yaitu Skala Kecemasan, Skala Religiusitas dan Skala Penerimaan Diri.

Uji asumsi yang dilakukan dalam penelitian ini meliputi uji linearitas hubungan, uji heteroskedastisitas, uji normalitas sebaran data. Hasil uji linearitas hubungan variabel religiusitas dan variabel kecemasan menunjukkan hubungan linear dengan nilai $\mathrm{F}=5,484$ dan signifikansi 0,026 $(\mathrm{p}<0,05)$. Hasil uji linearitas hubungan variabel religiusitas dan variabel penerimaan diri menunjukkan hubungan linear dengan nilai $\mathrm{F}=15,033$ dan $\mathrm{p}=0,001$ $(\mathrm{p}<0,01)$. Hasil uji linearitas variabel penerimaan diri dengan variabel kecemasan menunjukkan hubungan linear dengan nilai $\mathrm{F}=40,230$ dan $\mathrm{p}<0,0001$. Dari hasil analisis tersebut dapat disimpulkan bahwa hubungan antara ketiga variabel bersifat linear.

Uji Heteroskedastisitas dilakukan untuk menguji apakah dalam sebuah model regresi, terjadi ketidaksamaan varians dari residual dari satu pengamatan ke pengamatan yang lain. Salah satu metode statistik yang dapat digunakan untuk menetukan apakah suatu model terbebas dari masalah heteroskedastisitas atau tidak adalah Uji Glejser.

Hasil uji normalitas terhadap skala religiusitas menghasilkan nilai $Z_{K S}=0,609$ dengan signifikansi $0,852 \quad(p>0,05)$ ini menunjukkan bahwa data berdistribusi normal. Hasil uji normalitas terhadap skala penerimaan diri menghasilkan nilai $Z_{\mathrm{KS}}=0,636$ dengan signifikansi 0,814 $(\mathrm{p}>0,05)$ ini menunjukkan bahwa data berdistribusi normal. Hasil uji normalitas terhadap skala kecemasan menghasilkan nilai $Z_{K S}=0,501$ dengan signifikansi 0,964 ( $>0,05)$ ini menunjukkan bahwa data juga berdistribusi normal. Berdasarkan hasil uji normalitas terhadap hasil skor ketiga skala dengan 78 subjek dapat disimpulkan bahwa skor ketiga skala tersebut berdistribusi normal.

Metode yang digunakan untuk menguji hipotesis dalam penelitian ini adalah dengan analisis regresi untuk melihat hubungan antar variabel dan analisis mediator yaitu Sobel Test. Sobel Test juga digunakan untuk melihat pengaruh tidak langsung variabel independen pada variabel dependen melalui variabel mediator.

Berdasarkan hasil analisis mediasi Sobel Test, diperoleh hasil pengaruh total variabel religiusitas terhadap variabel kecemasan $b(Y X)=-0,5912 ; \quad p=0,0263$ $(\mathrm{p}<0,05)$. Angka tersebut menunjukkan bahwa ada hubungan negatif yang signifikan antara religiusitas dengan kecemasan. Hasil pada Tabel 8 di atas menunjukkan bahwa religiusitas memiliki peranan yang signifikan terhadap kecemasan. Hasil yang 
berikutnya adalah pengaruh variabel religiusitas terhadap variabel penerimaan diri yang diajukan sebagai mediator yaitu $b(M X)=0,5134 ; p=0,0006 \quad(p<0,01)$. Hasil analisis tersebut menunjukkan bahwa ada hubungan positif yang signifikan antara religiusitas dengan penerimaan diri. Hasil tersebut juga menunjukkan bahwa religiusitas memiliki peranan yang sangat signifikan terhadap penerimaan diri.

Tabel 1. Hasil Analisis Mediasi Sobel Test

\begin{tabular}{|l|c|l|}
\hline \multicolumn{3}{|c|}{ Direct and Total Effects } \\
\hline & $\begin{array}{c}\text { Koefisien } \\
\text { Regresi }\end{array}$ & Signifikansi \\
\hline b(YX) & $-0,5912$ & 0,0263 \\
\hline b(MX) & 0,5134 & 0,0006 \\
\hline b(YM.X) & $-1,3559$ & 0,0000 \\
\hline b(YX.M) & $-0,1049$ & 0,6410 \\
\hline
\end{tabular}

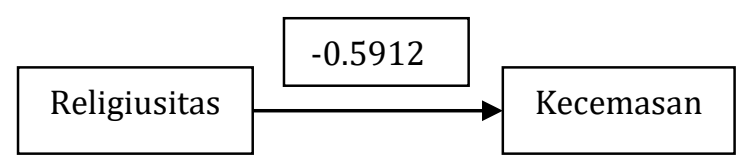

Gambar 1 Model Mediasi

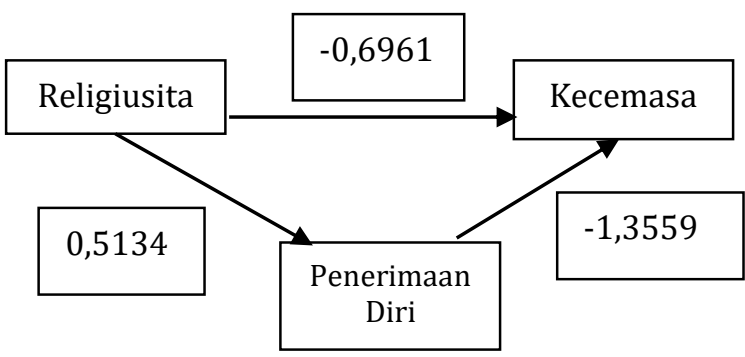

Hasil analisis mediasi yang ketiga adalah hasil pengaruh variabel penerimaan diri terhadap variabel kecemasan dengan mengendalikan variabel religiusitas $b(Y M . X)=-1,3599 ; p<0,0001(p<0,01)$. Dapat disimpulkan bahwa penyandang diabetes yang memiliki penerimaan diri yang tinggi, cenderung memiliki kecemasan yang rendah, dengan atau tanpa adanya aspek religiusitas. Hasil selanjutnya adalah pengaruh langsung variabel religiusitas terhadap variabel kecemasan dengan mengendalikan variabel penerimaan diri yaitu b(YX.M)=-0,1049; $p=0,6410(p>0,05)$. Hal ini mengindikasikan bahwa tidak ada hubungan antara religiusitas dengan tingkat kecemasan dengan mengendalikan penerimaan diri. Dapat disimpulkan bahwa dengan mengendalikan penerimaan diri, maka religiusitas tidak mempunyai peranan yang signifikan terhadap kecemasan.

Analisis mediasi Sobel Test juga menunjukkan hasil pengaruh tidak langsung dari variabel religiusitas terhadap variabel kecemasan melalui variabel penerimaan diri sebesar -0,6961; $\mathrm{p}=0,0019(\mathrm{p}<0,01)$, yang menunjukkan bahwa religiusitas mempunyai peranan yang sangat signifikan terhadap kecemasan dengan melalui penerimaan diri. Dengan kata lain, penerimaan diri subjek merupakan perantara hubungan antara religiusitas dengan kecemasan.

\section{b) Pembahasan}

Berdasarkan hasil analisis mediasi yang telah dipaparkan di atas menunjukkan bahwa ada hubungan negatif yang signifikan antara religiusitas dengan kecemasan $(b(Y X)=-0,5912 ; p=0,0263$ dan $p<0,05)$. Ini menunjukkan bahwa semakin tinggi tingkat religiusitas maka semakin rendah kecemasan. Hipotesis 1 diterima bahwa ada hubungan yang negatif antara religiusitas dengan kecemasan pada penyandang diabetes tipe 2. Semakin tinggi tingkat religiusitas maka akan semakin rendah kecemasan yang dialami penyandang diabetes tipe 2. Sebaliknya, semakin rendah tingkat religiusitas maka akan semakin tinggi kecemasan yang dialami penyandang diabetes tipe 2 .

Hasil penelitian pada 78 subjek penyandang diabetes, menunjukkan adanya hubungan negatif yang signifikan antara religiusitas dengan kecemasan. Faktor religiusitas tampaknya mempunyai peranan yang penting dalam menentukan kondisi psikologis seseorang. Berdasarkan hasil penelitian yang telah dilakukan sebelumnya bahwa religiusitas berhubungan dengan kecemasan yang dialami oleh pasien dengan penyakit kronis (Morse, Afifi, Morgan, Stephenson, Reichert, Harrison, \& Long, 2009). Penelitian tersebut selanjutnya menjelaskan bahwa semakin tinggi tingkat religiusitas seseorang maka semakin rendah tingkat kecemasannya. Penelitian yang lain menyatakan bahwa seseorang yang memiliki dasar religiusitas yang baik 
berasosiasi dengan berkurangnya tingkat kecemasan yang dialami (Khalek, 2006; Rosmarin, Pargament, \& Mahoney, 2009). Hal tersebut dijelaskan oleh Koenig bahwa religiusitas dapat merepresentasikan sumber kekuatan dari kenyamanan, harapan, dan kebermaknaan (Koenig, 2009). Hasil analisis yang kedua menunjukkan bahwa ada hubungan positif yang sangat signifikan antara religiusitas dengan penerimaan diri $(b(M X)=0,5134 ; p=0,0006$ dan $\mathrm{p}<0,01)$. Ini menunjukkan bahwa semakin tinggi tingkat religiusitas maka semakin tinggi pula tingkat penerimaan diri yang dialami. Dapat disimpulkan bahwa ada hubungan positif yang signifikan antara religiusitas dengan penerimaan diri. Hipotesis 2 diterima bahwa ada hubungan yang positif antara religiusitas dengan penerimaan diri pada penyandang diabetes tipe 2. Semakin tinggi tingkat religiusitas maka akan semakin tinggi tingkat penerimaan diri penyandang diabetes tipe 2 . Sebaliknya, semakin rendah tingkat religiusitas maka akan semakin rendah pula tingkat penerimaan diri penyandang diabetes tipe 2 .

Hasil penelitian pada 78 subjek penyandang diabetes tipe 2 , menunjukkan adanya hubungan positif yang signifikan antara religiusitas dengan penerimaan diri. Faktor religiusitas mempunyai peranan yang penting dalam meningkatkan penerimaan diri seseorang, khususnya penyandang diabetes. Penyakit diabetes yang bersifat kronis, seringkali menimbulkan perasaan bersalah dan tidak berdaya pada diri subjek. Hal tersebut dapat membuat subjek cenderung berpikir negatif, menyalahkan diri sendiri serta menyalahkan Tuhan atas kondisi yang dialaminya dan tidak mampu menerima kondisi diri apa adanya. Religiusitas membantu subjek untuk mengembangkan penerimaan dirinya. Religious belief mampu menyokong internal locus of control sehingga mempengaruhi kesehatan mental seseorang (Almeida et al., 2006), mencegah seseorang melakukan tindakan yang membahayakan dirinya maupun orang lain, memotivasi perilaku prososial, meningkatkan rasa aman, dan mendorong rasa percaya diri seseorang (Koenig, 2009). Dari penjelasan tersebut diketahui bahwa religiusitas dapat meningkatkan penerimaan diri penyandang diabetes tipe 2 yang bersifat kronis.

Hasil analisis ketiga menunjukkan bahwa ada hubungan negatif yang signifikan antara penerimaan diri dengan kecemasan (b(YM.X) =-1,3599; $\mathrm{p}<0,0001$ dan $\mathrm{p}<0,01$ ). Ini menunjukkan bahwa semakin tinggi tingkat penerimaan diri penyandang diabetes tipe 2 maka akan semakin rendah tingkat kecemasan yang dialami. Sebaliknya, semakin rendah tingkat penerimaan diri penyandang diabetes tipe 2 maka akan semakin tinggi tingkat kecemasan yang dialami.

Hasil penelitian pada 78 subjek penyandang diabetes tipe 2 , menunjukkan adanya hubungan negatif yang signifikan antara penerimaan diri dengan kecemasan. Faktor penerimaan diri mempunyai peranan yang penting dalam mempengaruhi kecemasan yang dialami seseorang, khususnya penyandang diabetes tipe 2 . Menurut Pargament (1997), keberhasilan mengintegrasikan pengalaman menghadapi penyakit dengan keyakinan spiritual akan mempengaruhi penerimaan penderita dan mampu mengurangi kecemasan yang dialaminya. Pada seseorang yang memiliki masalah kesehatan, penerimaan diri dapat membantu mereka menerima diri apa adanya serta tidak menyalahkan diri sendiri atas kesalahan-kesalahan yang telah diperbuat (Macinnes, 2006).

Pengaruh tidak langsung dari variabel religiusitas terhadap variabel kecemasan melalui variabel penerimaan diri ditunjukkan oleh analisis mediasi Sobel Test sebesar -0,6961; $\mathrm{p}=0,0019 \quad(\mathrm{p}<0,01)$. Ini menunjukkan bahwa religiusitas mempunyai peranan yang sangat signifikan terhadap kecemasan melalui penerimaan diri. Penerimaan diri subjek merupakan perantara hubungan antara religiusitas dengan kecemasan. Dapat disimpulkan bahwa ada hubungan yang negatif antara religiusitas melalui penerimaan diri dengan kecemasan pada penyandang diabetes tipe 2. Semakin tinggi tingkat religiusitas melalui tingkat penerimaan diri yang tinggi pula maka akan semakin rendah kecemasan yang dialami penyandang diabetes tipe 2 . Semakin rendah tingkat religiusitas melalui tingkat penerimaan diri yang rendah pula maka akan semakin tinggi kecemasan yang 
dialami penyandang diabetes tipe 2. Dari hasil yang telah dipaparkan diatas, maka hipotesis 3 juga diterima. Menurut Pargament, religious belief dapat memberikan dukungan kepada orang-orang dengan masalah kesehatan melalui penerimaan, kesabaran, ketabahan dan resiliensi sehingga memiliki tingkat kecemasan yang rendah (Pargament et al., 2004).

\section{KESIMPULAN DAN SARAN}

Penelitian ini menguji hubungan antara religiusitas dengan kecemasan yang dimediasi oleh penerimaan diri. Kriteria untuk dilakukan analisis mediasi dapat terpenuhi sehingga uji hipotesis dengan analisis mediasi dapat dilakukan. Dari hasil analisis diketahui bahwa:

1. Ada hubungan negatif yang signifikan antara religiusitas dengan kecemasan. Semakin tinggi tingkat religiusitas maka akan semakin rendah tingkat kecemasan pada penyandang diabetes tipe 2. Sebaliknya, semakin rendah tingkat religiusitas maka akan semakin tinggi tingkat kecemasannya.

2. Ada hubungan positif yang signifikan antara religiusitas dengan penerimaan diri. Semakin tinggi tingkat religiusitas maka akan semakin tinggi penerimaan diri pada penyandang diabetes tipe 2 . Begitu juga sebaliknya, semakin rendah tingkat religiusitas maka akan semakin rendah pula penerimaan dirinya.

3. Ada hubungan negatif yang signifikan antara religiusitas melalui penerimaan diri dengan kecemasan. Semakin tinggi tingkat religiusitas pada penyandang diabetes tipe 2 melalui penerimaan diri yang tinggi pula, maka akan semakin rendah tingkat kecemasan yang dialaminya. Begitu juga sebaliknya, semakin rendah tingkat religiusitas penyandang diabetes tipe 2 melalui penerimaan diri yang rendah, maka semakin tinggi tingkat kecemasan yang dialami.

Selain kesimpulan yang telah dipaparkan di atas, dalam penelitian ini juga terdapat keterbatasan penelitian. Keterbatasan tersebut adalah: tidak mengkontrol variabel waktu lamanya sakit sehingga penelitian ini memiliki akurasi yang rendah \& masih terdapatnya simtomsimtom kecemasan yang bias dengan simtom diabetes sehingga sulit dibedakan manakah simtom yang benar-benar mewakili simtom kecemasan.

Saran yang diajukan berdasarkan hasil penelitian dan diskusi, yaitu:

1. Religiusitas diharapkan dapat dimiliki oleh penyandang diabetes tipe 2 untuk membantu dalam meminimalisasi munculnya kecemasan. Masih terdapatnya variabel lain yang berpengaruh terhadap kecemasan pada penyandang diabetes tipe 2, maka diharapkan bagi peneliti selanjutnya melakukan penelitian terhadap variabel-variabel yang terkait dengan kecemasan seperti lamanya subjek menyandang diabetes tipe

Selain itu, peneliti selanjutnya dapat meminimalisasi simtom-simtom kecemasan yang bias dengan diabetes.

\section{REFERENSI}

Alloy, L. B., Riskind, J. H., \& Manos, M. J. (2005). Abnormal psychology current perspective. New York: Mc Graw Hill.

Almeida, A. M., Neto, F. L., \& Koenig, H. G. (2006). Religiousness and mental health: a review. Rev Bras Psiquiatri, 3 (1), 8-21.

Ambarwati, W. (2008). Hubungan antara persepsi dukungan sosial dengan tingkat kecemasan pada penderita diabetes mellitus. (Skripsi, tidak diterbitkan). Surabaya: Universitas Airlangga.

Ancok, D. (1989). Teknik penyusunan skala pengukur. Yogyakarta: Pusat Penelitian Kependudukan Universitas Gadjah Mada.

Asmadi, C. N. (2008, 9 Agustus). Diabetes Mellitus, Jumlah Penderita di Indonesia Keempat Dunia. Diunduh dari http://sehatdiabetes mellitus.blogspot.com/2008/08/diabete smellitus-mellitus-jumlah-penderitadi.html pada 24 Januari 2011. 
Azwar, S. (2006). Penyusunan Skala Psikologi. Yogyakarta: Pustaka Pelajar.

Badaria, H. (2004). Religiusitas dan penerimaan diri pada penderita diabetes mellitus. Jurnal Psikologika, 9 (17), 1-9.

Baron, R. M \& Kenny, D. A. (1986). The moderator-mediator variable distinction in social psychological research: conceptual, strategic, and statistical considerations. Journal of Personality and Social Psychology, 51 (6), 1173-1182. doi: 0022-3514/86/\$00.75

Chamberlain, J. \& Haaga, D. (2001) Unconditional self acceptance and psychological health. Journal of Rational Emotive and Cognitive Behavior Therapy 19, 163-176. doi:10.1023/A:1011189416600

Chaplin, J. P. (2004). Kamus lengkap psikologi. Jakarta : PT.Raja Grafindo Persada.

Clark, N. M., Gong, M., \& Kaciroti, N. (2007). A model of self-regulation for control of chronic disease. Health Education Behavior, 28, 769-782. doi:10.1177/109019810102800608

Collins, M. M., Corcoran, P., \& Perry, I. J. (2008). Psychology anxiety and depression symptoms in patients with diabetes mellitus. Diabetic Medicine, 26, 153-161. doi:10.1111/j.1464$5491.2008 .02648 \mathrm{x}$

Cronbach, L. J.(1963). Educational psychology. New York: Harcourt, Brace \& World, Inc.

Cunningham, K., Wolbert, R., Graziano, A., \& Slocum, J. (2005). Acceptance and change: the dialectic of recovery. Psychiatric Rehabilitation Journal, 29 (20), 146-148.

Delmar, C., Boje, T., Dylmer, D., Forup, L., Jakobsen, C., Moller, M., Sonder, H., \& Pedersen, B. D. (2005). Achieving harmony with oneself: life with a crhonic illness. Scandinavia's Journal Caring Science, 19, 204-212.
Dewi, C. (2008). Hubungan antara religiusitas dengan kecemasan menghadapi kematian pada lanjut usia (Skripsi, tidak diterbitkan). Fakultas Psikologi Universitas Gadjah Mada, Yogyakarta.

Durand, V. M. \& Barlow, D. H. (2006). Essentials of abnormal psychology. California: Thomson Wadsworth.

Fisher, L., Skaff, M. M., Mullan, J. T., Areant, P., Glasgow, R., \& Masharani, U. (2008). Psychological Issues : A longitudinal study of affective and anxiety disorders, depressive affect and diabetes mellitus distress in adults with Type 2 diabetes mellitus. Diabetic Medicine, 25, 10961101. doi:10.1111/j.14645491.2008.02533x

Flett G., Besser A., Davis R. \& Hewitt P. (2003) Dimensions of perfectionism, unconditional self acceptance and depression. Journal of Rational Emotive and Cognitive Behavior Therapy, 21, 119138.

Hall, R. C. W. \& Hall, R. C. W. (2010). Anxiety and endocrine disease. Seminars in Clinical Neuropsychiatry. Diakses dari http://www.drrichardhall.com/ Articles/anxiety.pdf pada 8 Juni 2011.

Handayani, M. M., Retnowati, S., Helmi, A. F. (1998). Efektivitas pelatihan pengenalan diri terhadap peningkatan penerimaan diri dan harga diri. Jurnal Psikologi, 2, 4755 .

Hathaway, W. L. \& Pargament, K. I. (1991). Intrinsic religiousness, religious coping, and psychosocial competence: A covariance structure analysis. Journal for the Scientific Study of Religion, 29, 423441.

Jersild, A. T. (1965). The psychology of adolesence. New York: The MacMillan Company.

KedaiObat. (2010, 17 April). Prevalensi/angka kejadian diabetes mellitus di Indonesia. Diunduh dari 
http://www.kedaiobat.co.cc/2010/04/p revalensi-kejadian-di.html pada 24 Januari 2011.

Khalek, A. M. A. (2006). Happiness, health, and religiosity: Significant relations. Mental Health, Religion \& Culture, 9(1), 85-97. doi: $10.1080 / 13694670500040625$

Khuwaja, A. K., Lalani, S., Dhanani, R., Azam, I. S., Rafique, G., \& White, F. (2010). Anxiety and depression among outpatients with type 2 diabetes: A multicentre study of prevalence and associated factors. Diabetology \& Metabolic Syndrome Journal, 2 (72).

Koenig, H. G. (2009). Research on religion, spirituality, and mental health. The Canadian Journal of Psychiatry, 54 (5), 283-291.

Lee, B. Y. \& Newberg, A. B. (2005). Religion and health: A review and critical analysis. Journal of Zygon, 40 (2).

Li, C., Barker, L., Ford, E. S., Zhang, X., Strine, T. W., \& Mokdad, A. H., (2008). Diabetes and anxiety in US adults: findings from the 2006 behavioral risk factor surveillance system. Diabetic Medicine, 25 , 878-881. doi:10.1111/j.14645491.2008.02477.x

Macinnes, D. L. (2006). Self-esteem and selfacceptance: an examination into their relationship and their effect on psychological health. Journal of Psychiatric and Mental Health Nursing, 13, 483-489.

Maramis, W. F. (1998). Catatan ilmu kedokteran jiwa. Surabaya: Airlangga University Press.

Morse, C. R., Afifi, W. A., Morgan, S. E., Stephenson, M. E., Reichert, T., Harrison, T. R., \& Long, S. D. (2009). Religiosity, anxiety, and discussions about organ donation: Understanding a complex system of associations. Journal of Health
Communication, $\quad 24, \quad 156-164$.
doi:10.1080/10410230802676755

Novvida, K. (2007). Penerimaan diri dan stres pada penderita diabetes mellitus (Skripsi, tidak diterbitkan). Universitas Islam Indonesia, Yogyakarta.

Paddison, C. A. M, Eborall, H. C., French, D. P., Kinmonth, A. L., Prevost, A. T., Griffin, S. J., \& Sutton, S. (2011). Predictors of anxiety and depression among people attending diabetes screening: A prospective cohort study embedded in the ADDITION (Cambridge) randomized control trial. British Journal of Health Psychology, 16, 213-226.

doi:10.1348/135910710X495366

Pargament, K. I. (1997). The psychology of religion and coping: Theory, research, practice. New York: The Guilford Press.

Pargament, K. I., Kennell, J., Hathaway, W., Grevengoed, N., Newman, J., \& Jones, W. (1988). Religion and the problem-solving process: Three styles of coping. Journal for the Scientific Study of Religion, 27, 90104.

Pargament, K. I., Koenig, H. G., Tarakeshwar, N., \& Hahn, J. (2004). Religious coping method as predictors of psychological, physical and spiritual outcomes among medically ill elderly patients: a two year longitudinal study. Journal of Health Psychology, 9 (6), 713-730.

Paul, G. M., Smith, S. M., Whitford, D. L., O'Shea, E., O'Kelly, F \& O'Dowd, T. (2007). Peer support in type 2 diabetes: a randomised controlled trial in primary care with parallel economic and qualitative analyses: pilot study and protocol. Journal of BioMed Central, 8 (45). doi:10.1 186/1471-2296-8-45

Pfeifer, S. \& Waelty, U. (1999). Anxiety, depression, and religiosity: A controlled 
clinical study. Journal of Mental Health, Religion \& Culture, 2 (1), 35-45. doi:13674676/99/010035-11

Pinel, J. P. J. (1997). Biopsychology $3^{\text {th }}$ edition. Boston: Allyn \& Bacon.

Preacher, K.J \& Hayes, A.F. (2004). SPSS aand SAS procedures for estimating indirect effects in simple mediation models. Journal of Behavior Research Methods, Instruments, \& Computers, 36 (4), 717731

Rahmandani, A. (2011). Pengaruh terapi pemaafan untuk meningkatkan penerimaan diri pada penderita kanker payudara (Tesis, tidak diterbitkan). Fakultas Psikologi Universitas Gadjah Mada, Yogyakarta.

Ristow, M. (2010). Neurodegenerative disorders associated with diabetes mellitus. Department of Clinical Nutrition, German Institute for Human Nutrition. Diakses dari http://www.ncbi.nlm.nih.gov/pubmed/ 15175861 pada 29 Juni 2010.

Rosmarin, D. H., Pargament, K. I., \& Mahoney, A. (2009). The role of religiousness in anxiety, depression, and happiness in a Jewish community sample: A preliminary investigation. Mental Health, Religion \& Culture, 12 (2), 97-113. doi: 10.1080/13674670802321933

Rothenbacher, D., Ruter, G., \& Brenner, H. (2006). Prognostic value of physicians' assessment of compliance regarding allcause mortality in patients with type 2 diabetes: primary care follow up study. BioMedicine Central Family Practice, 7 (42). doi:10.1186/1471-2296-7-42

Roupa, Z., Koulouri, A., Sotiropoulou, P., Makrinika, E., Marneras, X., Lahana, I., \& Gourni, M. (2009). Anxiety and depression in patients with type 2 diabetes mellitus, depending on sex and body mass index. Health Science Journal, 3 (1), 32-40.
Sanderson, F. H. \& Reilly, T. (1983). Trait and state anxiety in male and female crosscountry runners. Britania Journal Sports Medicine, 17 (1), 24-26.

Santrock, J. W. (2002). Life-span development. Perkembangan masa hidup jilid 2. Jakarta: Erlangga.

Sarafino, E. P. (1998). Health psychology: Biopsychosocial interactions. New York: John Wiley \& Sons.

Seeman, T. E., Dubin, L. F., \& Seeman, M. (2003). Religiosity/spirituality and health: A critical review of the evidence for biological pathways. Journal of American Psychologist Association, 58 (1), 53-63. doi:10.1037/0003-066X.58.1.53

Seybold, K. S. \& Hill, P. H. (2001). The role of religion and spirituality in mental and physical health: Current directions in psychological science. Journal of American Psychological Society, 10 (1), 21-24.

Sloan, F. A., Padron, N. A., \& Platt, A. C. (2009). Preferences, beliefs, and selfmanagement of diabetes. Health Services Research, $44 \quad$ (3), 1068-1087. doi:10.1111/j.1475-6773.2009.00957.x

Sousa, V. D., Hartman, S. W., Miller, E. H. \& Carroll, M. A. (2009). New measure of diabetes self-agency, diabetes selfefficacy, and diabetes self-management for insulin-treated individuals with type 2 diabetes. Journal of Clinical Nursing, 18, 1305-1312. doi:10.1111/j.13652702.2008.02729.x

Soeharjono, L. B., Tjokroprawiro, A., Adi, S. (2002). Diabetes mellitus tergantung insulin (DM-TI): Aspek psikologis penderita dan keluarga. Anima, Indonesian Psychological Journal, 17 (2), 161-169.

Sridhar, G.R., Madhu, K. (2002). Psychosocial and cultural issues in diabetes mellitus. Journal of Current Science, 83 (12), 15561564. 
Sustrani, L., Alam, S., \& Hadibroto, I. (2004). Diabetes mellitus. Jakarta : PT. Gramedia Pustaka Utama.

Suyono, S. (2009). Kecenderungan peningkatan jumlah penyandang diabetes mellitus. Dalam penatalaksanaan diabetes mellitus terpadu. Editor : Soegondo, S. Soewondo, P., \& Subekti, I. Jakarta : Balai Penerbit FKUI.

Taylor, S. E. (2006). Health Psychology $6^{\text {th }}$ Edition. New York: Mc.Graw-Hill.

Tuncay, T., Musabak, I., Gok, D. E., \& Kutlu, M. (2008). The relationship between anxiety, coping strategies and characteristics of patients with diabetes mellitus. Health and Quality of Life Outcomes, 6 (79). doi:10.1186/14777525-6-79

Wachtel, P. L. (2005). Anxiety, consciousness, and self-acceptance: Placing the idea of making the unconscious conscious in an integrative framework. Journal of Psychotherapy Integration, 15 (3), 243-253. doi: 10.1037/1053-0479.15.3.243

Wardhani,F. P. I. (2007). Hubungan antara religiusitas dengan penerimaan diri pada penyandang cacat tubuh (Skripsi, tidak diterbitkan). Fakultas Psikologi Universitas Gadjah Mada, Yogyakarta.

Wikipedia. (2011). Diunduh dari http://id.wikipedia.org/w/index.php?titl $\mathrm{e}=$ Kelainan

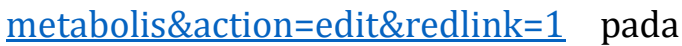
14 April 2011.

Winasis, E. B. (2009). Hubungan antara konsep diri dengan depresi pada penderita diabetes di Puskesmas Pracimantoro Wonogiri (Skripsi, tidak diterbitkan). Fakultas Ilmu Kesehatan Universitas Muhammadiyah Surakarta, Surakarta.

Yudo, A. (2009, 13 November). Tahun 2030 Prevalensi Diabetes Melitus Di Indonesia Mencapai 21,3 Juta Orang. Diunduh dari http://sehatdiabetes.blogspot. com/2008/08/diabetes-mellitusjumlah-penderita-di.html pada 22 Maret 2011.

Zalewska, A., Miniszewska, J., Chodkiewicz, J., \& Narbutt, J. (2007). Acceptance of chronic illness in psoriasis vulgaris patients. Journal of European Academy of Dermatology and Venereology, 21, 235242. doi:10.1111/j.14683083.2006.01912. 